\title{
Several Suggestions on Development of Tourism Economy in China
}

\author{
Changjing Wei \\ Qingdao Huanghai University, Qingdao 266427
}

\author{
Keywords: Tourism economy; Development status; Suggestion
}

\begin{abstract}
Tourism economy plays a great role for China's social and economic development. In recent years, China has paid special attention to developing multiple tourism resources so as to make them better serve for development of social economy. However, during development of tourism resources, various problems will inevitably appear and seriously hinder healthy development of tourism economy. This paper mainly discusses basic concept of tourism economy, sets forth the importance of tourism economy in China's development as well as current development status and finally proposes several suggestions and countermeasures for development of tourism economy in China.
\end{abstract}

\section{Introduction}

In China, tourism economy is a new industry and also a sunrise industry of future economic development in China. It accounts for nearly 1/10 of GNP and plays a pillar role for China's economic development. Tourism economy is the sum of activity relations of all tourism economy with the basic content of development of tourism and commodity economy. As social and economic development in China continuously alters, new requirements are also proposed for development of tourism economy. However, due to effects of multiple factors, China's tourism economic development system is not perfect and has many defects. Thus, it is necessary to overall analyze and study causes of these problems and put forward countermeasures for healthy and rapid development of China's tourism economy.

\section{Overview of tourism economy}

Tourism economy means tourism is regarded as the subject of economic development and that tourist activities are deemed as the foundation of tourism economic development. Tourism-related activities and all economic activities are well linked through vigorous development of tourist commodity economy with the help of advanced technological means to make them go through the whole process of tourism economic development. Tourism economy refers to the sum of multiple tourism economic benefits reflected by multiple economic behaviors which are generated by tourist subject and operation subject of tourist activities according to different interests. Tourism economy mainly includes basic necessities of life and entertainment in tourism process, production and operation activities of tourism enterprises and development dynamics of the whole tourism market. It is the first sub-system of economic development in china and plays a great promotion role for social and economic development ${ }^{[1]}$.

\section{Importance of development of tourism economy in China}

A).Tourism economy can rationally adjust China's economic structure and greatly drive healthy development of relevant industrial economic activities and industry. Tourism is a dominant industry and green industry and also significant foundation of economic development. Active development of tourism economy can not just well integrate with international economic development, but also drive domestic demand of economic development to a large extent, then facilitate scientific adjustment of economic development structure and promote healthy and rapid economic development. 
B). Development of tourism economy can relieve China's employment pressure to some extent and solve employment issue. Tourism economy involves a wide range, ranging from food, clothes, accommodation, traveling and buying in the tourism process to multiple tourism-related behaviors. These activities can create different employment opportunities directly or indirectly and reach the win-win purpose of tourism economy and employment ${ }^{[2]}$.

C). The most important function of development of tourism economy is to facilitate rapid development of local and regional economy. Vigorous development of tourism economy can gradually expand revenue scope, drive construction and development of municipal construction, traffic, water and electricity supply as well as advanced communication equipment in the region where tourism develops. Meanwhile, this can greatly promote steady and healthy development of local economy.

\section{Development status of China's tourism economy}

\section{Overall service level in China' tourism is low}

Fundamentally, development of tourism economy is the improvement of service level and quality in tourism. As foreign and domestic tourism development competitions become increasingly fierce, the function of tourism service quality in the whole tourism economic development is especially important. According to relevant statistic analysis, in China's tourism development, phenomenon of low tourism service quality and level is very serious, which greatly impedes development of China's tourism economy. In particular, some medium and small tourism enterprises blindly pursue economic development benefits and ignore improvement of tourism development quality and level. Thus, service level in the whole tourism industry is low. The causes for the phenomenon mainly lie in two aspects:

A). Continuous development of society and economy in China makes people pursue higher life quality and pay attention to travelling so as to reach the purpose of enjoyment and relaxation. Thus, the demand exceeds supply in China's tourism. Especially in some medium and long vacations, there are very numerous tourists in each famous tourist area. Thus, tourism development units only focus on promotion of economic benefit and ignore improvement of service quality ${ }^{[3]}$.

B). China's tourism lacks professional tourism talents. China's tourism ignores cultivation of professional talents in the development process. Relevant tourism human resource management system is imperfect, and there is short of high-level and highly-educated professional talents in tourism development process. Thus, service quality and level cannot improve in the process of tourism development.

C). Tourism is an economic industry without national boundaries. It should not just face domestic tourists, but also accept and service foreign tourists. But, China lacks professional tourism talents. Foreign language application level is low. Service capacity for foreigners is insufficient. Meanwhile, service quality of various scenic spots and hotels is not high. Thus, it is very hard for China's tourism to establish favorable tourism image in international market. This seriously hinders promotion of tourism service quality.

\section{Relevant guarantee system is imperfect in development of tourism economy}

Firstly, administrative system of tourism is imperfect. The problems and contradictions cannot be overall managed and handled in concrete operation. Meanwhile, there is still serious tourism management malposition phenomenon. Favorable tourism management effect cannot be reached. Secondly, guarantee system of tourism development is imperfect. In development of tourism economy, a universal problem is that tourism marketing awareness is not strong. Thus, energy input and public guarantee system construction for development of tourism resources are ignored. Infrastructure of tourism development cannot be effectively supplied, and people's requirements cannot be met. Thirdly, there is short of related legal guarantee system for development of tourism economy. Thus, vicious competition will be caused during resource development. This is adverse to good development of tourism economy. 


\section{No sound and scientific promotion mechanism drives development of tourism economy}

In recent years, although the government of China and society has started to focus on operation of tourism economy and formulated a series of relevant development measures, development level of China's tourism economy cannot improve on the whole due to no related promotion mechanism. Firstly, the subject of tourism economic development market is unclear. The government of China excessively intervenes in development and application of some large-scale tourism resources. Thus, varieties of tourism development products are not rich, and there is short of key tourism product competitiveness. Secondly, coordinated management is insufficient for key tourism development area. Because tourism development area is not well managed, vicious competition for tourism resources happens frequently in tourism resource development ${ }^{[4]}$. Thirdly, there is no rational and scientific competition development mechanism during development of tourism economy. In China's the subjects of government and enterprise leaders are not specific during concrete development of tourism. There is no rational competition and incentive mechanism, which is adverse to development of tourism economy.

\section{Several suggestions and countermeasures for development of tourism economy}

To develop China's tourism economy, it is necessary to improve service level of tourism

Overall service quality of tourism is the key to achieving rapid and healthy development of tourism economy. Both the government and society must value its importance, and improve tourism service level and quality. Specific measures include the following: firstly, it is required to pay attention to cultivating professional tourism talents. Professional tour guides and commentators should be cultivated in accordance with development status and trend of tourism. Meanwhile, incentive and competition mechanisms for employees should be established again to improve their moral accomplishment and professional quality and enhance their service level. Secondly, hardware infrastructure construction for tourism development must be valued. To achieve healthy and rapid development of tourism economy, it is necessary to take into account of requirements of domestic and overseas tourists for hardware facilities, enhance infrastructure construction and continuously meet tourists' quality demand. Meanwhile, tourism service level supervision and administration system should be perfected. Relevant tourism organizations should focus on tourists' feedback information on service quality anytime so as to realize service problems in development of tourism economy in time and take effective measures. Besides, tourism management system and tourism service level guarantee system should be perfected so as to reach the purpose of formation of good competitiveness $^{[5]}$.

\section{Perfect guarantee system for development of China's tourism economy}

Sound tourism development guarantee system is the foundation for development of tourism economy. Specific guarantee system measures include the following: firstly, perfect current tourism supervision and management system. Tourism management is disperse and local. Thus, it is necessary to integrate such type of supervision and management, establish favorable tourism supervision and management idea, promote reform of supervision and management system and enhance tourism management level; secondly, perfect public foundation guarantee system of tourism economic development. The government and society need to attach importance to public infrastructure construction, increase construction investment, perfect increasingly diversified public infrastructure, continuously meet tourists' quality service requirements and boost their satisfaction rate for tourism facilities; thirdly, perfect legal regulations on tourism economic development. The government should lay down some rules and regulations to perfect tourism resource development, restrain vicious development of tourism economy and create good legal protection environment for development of tourism economy.

\section{Perfect incentive and competition mechanisms for development of tourism economy}

Favorable incentive and competition mechanisms can inject new vigor and bring new opportunities for development of tourism economy. It is required to focus on perfecting incentive and competition mechanisms for development of tourism economy. Firstly, tourism enterprises should be 
cultivated to the subject leading development of tourism economy. In previous development of tourism economy, the government often intervenes in tourism resource development and tourism economic development. This is adverse to forming rich tourism product market and active competition mechanism. Hence, it is necessary to reduce unnecessary interference by the government, cultivate tourism enterprises to the guiding subject of tourism market and actively lead tourism economy to better develop. Secondly, it is necessary to enhance governmental supervision and management. To develop tourism economy in China, it is required to coordinate and communicate with different tourism area and different tourism resources, enhance governmental supervision and management, further standardize development behaviors of tourism and ensure orderly and favorable development of tourism economy. Thirdly, perfect tourism market mechanism and intensify macro-management. To develop tourism economy, it is required to intensify macro-management, reform and optimize operation pattern of tourism enterprises, blend tourism enterprises in development of market economy and make them achieve independent operation and assume sole responsibility for profits or losses so as to boost market competitiveness of tourism enterprises, improve development force of tourism products and promote development of tourism economy.

It is required to concentrate tourism funds from multiple aspects and boost investment benefits of tourism investment benefits

Investment force of tourism development in China is insufficient so that large quantities of tourism resources cannot be developed. In addition, public infrastructure construction is also insufficient. This seriously hinders development of tourism economy. Hence, it is required to conduct intensive investment through various channels. The state should attach importance to investment in tourism resources and carry out special appropriation and special loan for tourism. This is a major capital source way for development of tourism construction. Meanwhile, tourism enterprises should actively reform operation management way, reduce tourism management cost, try to achieve self-accumulation and self-breakthrough and facilitate development of tourism economy. Moreover, other industries should be encouraged to invest in tourism development, add in the list of construction and development of tourism construction, achieve effectively fund utilization, boost infrastructure construction quality of tourism enterprises, intensify tourism resource development and improve development level of tourism economy.

\section{Conclusions}

At present, tourism economy has become an important constituent part of economic development. It is a sunrise industry and pillar industry of China's economy in the future. In recent years, although multiple development protection measures and systems are taken, many problems still exist in actual development process. Development status of tourism is not optimistic. Hence, it is required to carefully analyze and study these problems, find out the causes and adopt measures and countermeasures, formulate related legal laws and regulations, perfect and enhance public infrastructure construction, improve service quality and level in Chinese tourism and facilitate healthy and rapid development of Chinese tourism economy.

\section{References}

[1] Zheng $\mathrm{Yu}$, On functions of China's exhibition tourism economy and suggestions [J]. China Business \& Trade, 2010,(26):175-176.

[2] Zhou Song, Analysis of development status of Chinese tourism economy and relevant suggestions. China Business \& Trade, 2012,(12):21.

[3] Zhang Xiaoli, Adjustment of Chinese tourism economy with legal means. Modern Economic Information, 2014,(16):359-359.

[4] Liu Yangyang, Study on development of core competitiveness of tourism economy in Baoding City. Hebei University of Technology, 2009,(16):105-106. 
[5] Yuan Weizhong, Study on problems and countermeasures of tourism economic development. Modern Economic Information, 2013,(11):327-327. 